\title{
Farklı Spor Dallarında Görev Yapan Hakemlerin Karar Verme Stillerinin İncelenmesi
}

\author{
Demet ÖZTÜRK ÇELIK ${ }^{1 *}$ (1) \\ ${ }^{1}$ Osmaniye Korkut Ata Üniversitesi, Beden Eğitimi ve Spor Yüksekokulu, OSMANIYE
}

DOI: 10.31680/gaunjss.776473

Orijinal Makale / Original Article

Geliş Tarihi / Received: 02.08.2020

Kabul Tarihi / Accepted: 13.10.2020

Yayın Tarihi / Published: 14.12.2020

\section{Öz}

Bu araştırmada spor müsabakalarını yöneten hakemlerin karar verme stillerinin çeşitli sosyo-demografik değişkenlere göre incelenmesi amaçlanmıştır. Araştırma 2019-2020 yılında vizesini yaptırmış sezon içerisinde spor müsabakası yöneten futbol, basketbol, voleybol federasyonlarında görev alan 109 hakem ile gerçekleştirilmiştir. Araştırma verileri Mann ve ark. (1998) tarafından geliştirilmiş ve Türkçe 'ye Deniz (2004) tarafından uyarlaması yapılan Melbourne Karar Verme Ölçeği kullanılmıştır. Verilerin analizinde, SPSS istatistik paket yazılımı kullanıımışıı. Gerçekleştirilen Kolmogorov-Smirnov ve Shapiro-Wilk normallik testleri sonucunda verilerin normal dağıım varsayımını karşılamadığı belirlenmiştir. Katııımcıların tanıtıcı özelliklerine göre karar verme puanlarını karşılaştırmak amacıyla Mann-Whitney $\mathrm{U}$ ve Kruskal Wallis $\mathrm{H}$ parametrik olmayan hipotez testleri uygulanmıştır. Hakemlerin karar verme puanlarının federasyon, hakemlik yılı değişkenine göre istatistiksel olarak anlamlı farklılık gösterdiği belirlenmiştir ( $p<.05)$. Gerçekleştirilen Dunn-Bonferroni post-hoc testi sonucunda kaçıngan karar verme puanlarındaki farklıığın voleybol- basketbol, futbol- basketbol gruplarından, öz saygı puanlarındaki farkılığın 1-5, 11-15 hakemlik yılı gruplarından kaynaklandığı tespit edilmiştir. Sonuç olarak; futbol, basketbol, voleybol hakemlerinin karar verme stillerinin cinsiyet, eğitim, medeni durum değişkenlerine göre anlamlı bir farklılık göstermediği, karar vermenin alt boyutlarından biri olan kaçıngan karar verme stillerinin ise hakemlik yılı ve hakemlerin bağlı olduğu federasyonu belirten federasyon değişkenine göre farklılaşı̆ğı belirlenmiştir.

Anahtar Kelimeler: Spor, hakem, karar verme

\section{An Investigation of Decision-Making Styles of Referees Working in Various Sport Branches}

\begin{abstract}
The purpose of this study was to investigate the decision making skills of refrees from different branch of sports in terms of various socio-demographic variables. The research was conducted with total number of 109 refrees from different branch of sports (football, basketball, volleyball). The inclusion criteria for the participants was being a licenced referee and refereeing at least one sports competition in 2019-2020 season. The Melbourne Decision Making Questionnaire originally developed by Mann et al., (1998) was used in order to investigate the decision making skills of referees. The scale was translated to Turkish by Deniz (2004). All statistical analysis were performed using SPSS statistical software. Both Kolmogorov-Smirnov and Shapiro-Wilk tests were used in order to test the normality of the data. Therefore, both non-parametric Mann-Whitney $\mathrm{U}$ and Kruskal Wallis $\mathrm{H}$ tests were used in order to investigate decision making scores of participants in terms of various socio-demographic variables. The results of the study showed that the decision making scores of referees significantly differ by federation and years of seniority variables $(p<.05)$. A Dunn-Bonferoni post-hoc test was performed in order to find out the responsible groups causing the difference in decision making scores. The results of post-hoc test showed that "volleyball-basketball" and "football-basketball" groups were responsible for the differences in "avoidant decision making" scores. Moreover, the results of post-hoc tests revealed that "1-5" and "11-15" groups for years of seniority are responsible for the differences in self-esteem scores. As a result, it is determined that while the decision making skills of football, basketball and volleyball referees does not differ in terms of gender, education and marital status, the "avoidant decision making" skills of football, basketball and volleyball referees does significantly differ in terms of seniority and affiliated federation.
\end{abstract}

Keywords: Sport, referee, decision making 


\section{Giriş}

İnsan, doğası gereği biyolojik, psikolojik ve sosyal ihtiyaçları olan bir varlık olarak çevresiyle devamlı etkileşim halindedir. İnsanın doğumundan ölümüne kadar karşılaştığı birçok aşılması gereken problemi ve ulaşılması gereken hedefleri vardır. Tüm bu sorunları ortadan kaldırmak ve hedeflerine ulaşmak için sağlıklı kararlar alması gerekir (Çolakkadıŏlu, 2010). Bu sebeple, karar verme önemli bir yaşam becerisidir. Karar sözcüğü, "Bir iş veya sorun hakkında düşünülerek verilen kesin yargı, hüküm, düzenlilik" olarak tanımlanmıştır (TDK, 2020).

Karar kelimesi Latincede "decidere" kelimesinden gelmekte kesmek, kesintiye uğratmak anlamına gelmektedir. Dilimizde bir sorun veya olay karşısında düşünme ve muhakeme sonucunda hüküm vermeyi içerir (Tosun, 1992). Karar, eldeki imkanlarla hedefe ulaşmak için verilen çabayı içinde barındırır. Karar alma yalın haliyle sorunları çözmek anlamına gelir (Eskicioğlu ve ark., 2012). Karar verme ise içinde bulunduğumuz problemin çözümünde en doğru seçeneği tercih edebilmedir (Üngüren, 2011).

Karar verme davranışı, almamız gereken karar konusunda ön bilgi edinmek ve amaca ulaşabilmek için elde ettiğimiz bilgiler doğrultusunda seçenekler oluşturma ve en uygun seçeneği seçmeyi ifade eder (Güçray, 2001). Karar verme kolay gibi görünse bile karmaşık bir süreçtir (Pekdoğan, 2015). Bireyin birçok seçeneği değerlendirerek birisini uygulama seçtiği karmaşık aşamalar bütünü olarak tanımlamışlardır (Deniz, 2011).

Hakem sözcüğünün kökeni bu dilde 'başvurmak' sözcüğünden gelmektedir. TDK da ki tanımı ise "Tarafların aralarındaki anlaşmazlığı çözmek için yetkili olarak seçtikleri ve üzerinde anlaştıkları kişi, yargıcı, belirli bir konudan iyi anlayan kimse, seçme ve karar verme yetkisi bulunan kimse, karşılaşmaları, yarışmaları kurallara uygun ve yansız olarak yöneten kimse" şeklinde ifade edilmiştir (TDK, 2020). Durna (1997) Hakemi spor müsabakalarını yöneten, kazanılan sayıları tespit etme, kuralları uygulamak ve uygulatmak, spor müsabaka kurallarına uymayanları cezalandırmakla görevli kişilerdir şeklinde tanımlamıştır.

Hakem; bir olayı yatıştırmak, çözüm yolu bulmak için taraflarca seçilmiş kişilerdir. Başka bir ifadeyle tanımlamak gerekirse spor organizasyonlarını yapan ve sorumlu olan kişiler tarafından seçilmiş ve kuralları daha önceden resmi olarak belirlenmiş spor müsabakalarını yöneten, hatalı davranışlar karşısında ceza yaptırımları uygulayan ve bunları rapor eden, takımların aldıkları puanları müsabaka 
cetveline işleyen, spor organizasyonlarına katılan, sporcularla birlikte sahada mücadele eden, spor müsabaka sonuçlarını ilan eden görevli kişilerdir (Cengiz ve Pulur, 2004).

Spor müsabakalarında hakem kararlarının doğru ve gerekli sürede olması çok önemlidir. Bunun nedeni sporcuların oyun alanında hakem işaretlerini rahatlıkla anlayabilmesi ve verilen kararın doğru olması sporcunun konsantrasyonunu bozmadan oyuna dönmesine neden olur. Hatalı kararlarda antrenör ve sporcular tarafından hakem kararına yapılan itirazlar hem rakibin hem de kendi takım arkadaşlarının saha içerisinde durmasına ve oyundan soğumasına sebep olur.

İlgili literatür incelendiğinde hakemlerin karar verme stillerinin analiz edildiği çalışmaların tekil olarak belirli spor branşlarındaki hakemler üzerinde gerçekleştirildiği ve özellikle bazı spor dallarında yoğunlaştığı görülmektedir. Bununla birlikte, farklı spor dallarının birlikte incelendiği çalışmaların sınırlı sayıda olduğu görülmektedir. Bu nedenle, literatürdeki bu boşluğu gidermek ve farklı spor dallarında görev yapan hakemlerin karar verme düzeylerini çeşitli demografik değişkenlere göre birlikte incelemek amacıyla bu çalışma Osmaniye ilinde spor müsabakalarında görev yapan hakemler ile gerçekleştirilmiştir.

Bu bilgiler doğrultusunda bu araştırmanın amacı; spor müsabakaları yöneten hakemlerin karar verme sürelerinin doğru kararlarla örtüşebilmesi ve karar verme stillerinin araştırılmasıdır.

\section{Yöntem}

\section{Araştırmanın Modeli}

$\mathrm{Bu}$ çalışmada nicel araştırma modelinin tanımlayıcı ve betimsel tarama desenlerinden faydalanılmıştır. Tarama araştırmalarının amacı genellikle araştırma konusunu ile ilgili var olan durumun fotoğrafını çekerek bir betimleme yapmaktır (Büyüköztürk ve ark., 2017)

\section{Çalışma Grubu}

Çalışmanın örneklem grubunu belirlerken amaçlı örnekleme yöntemlerinden kolayda örnekleme yöntemi kullanılmıştır. Araştırmanın çalışma grubu, Osmaniye ilinde 2019-2020 sezonunda vizesini yaptırmış futbol, basketbol, voleybol spor dallarında faal olarak hakemlik yapan 109 hakem oluşturmaktadır. 


\section{Verilerin Toplanması}

Veri toplama araçları kişisel bilgi formu, Melbourne karar verme ölçeğinden oluşmaktadır. Kişisel bilgi formunda (cinsiyet, federasyonunuz, medeni durum, hakemlik yılı, eğitim durumu, hakemlik yaptığınız spor dalında antrenör olma) soruları yer almaktadır. Hakemlerin karar verme stillerini ölçmek amacıyla Mann ve ark., (1998) tarafından karar vermede öz saygı ve karar verme stillerini karşılaştırmak için geliştirilen Melbourne Karar Verme Ölçeği (Melbourne Decision Making Questionary) kullanılmıştır. Ölçek, Deniz (2004) tarafından Türkçeye uyarlanmış, geçerlilik ve güvenirlilik çalışması yapılmıştır. Ölçek iki kısımdan oluşmaktadır.

I. kısım: karar vermede öz saygı belirlemek için 6 ifadeden ve tek alt boyuttan oluşmaktadır.

II. kısım: karar verme stillerini belirlemek için 22 ifadeden ve dört alt boyuttan oluşmaktadır. Bunlar:

Dikkatli Karar Verme Stili: Bireyin karar vermeden önce özenle gerekli bilgiyi araması ve alternatifleri dikkatlice değerlendirmesi sonucunda seçim yapma durumudur. Bu alt ölçek (2-4-6-8-12-16) altı ifadeden oluşmaktadır.

Kaçıngan Karar Verme Stili: Bireyin karar vermekten kaçınması, kararları başkalarına bırakma eğiliminde olması ve sorumluluğu bir başkasına devrederek karar vermekten kurtulmaya çalışma durumudur. Bu alt ölçek (3-9-11-14-17-19) altı ifadeden oluşmaktadır.

Erteleyici Karar Verme Stili: Bireyin kararı geçerli bir sebebi olmamasına rağmen sürekli ertelemede bırakma durumudur. Bu alt ölçek (5-7-10-18-21) beş ifadeden oluşmaktadır.

Panik Karar Verme Stili: Bireyin bir karar durumu ile karşı karşıya kaldığında, kendini zaman baskısı altında hissederek aceleci davranışlar sergileyip çabuk çözümlere ulaşma çabası durumudur. Bu alt ölçek (1-13-15-20-22) beş ifadeden oluşmaktadır.

Bu çalışmada ölçeğin Cronbach's Alpha güvenirlik katsayısı .75 olarak hesaplanmıştır. Yazarın bağlı olduğu kurumdan etik kurul izni alındıktan sonra, spor federasyonlarının il temsilcilerinden sözlü izin alınmıştır. Google Forms Linki ile ölçeklerin doldurulması sağlanmıştır. Araştırmacı veriler toplanırken Google Forms Linki ile hakemlere ölçekler ve çalışma hakkında bilgi vermiştir. Anketlerin doldurulma süresi 10 -15 dakika süreceği tahmin edilmektedir. 


\section{Verilerin analizi}

Araştırma elde edilen verilerinin analizi SPSS paket programı yardımıyla gerçekleştirilmiştir. Hakemlerin tanıtıcı özellikleri için tanımlayıcı istatistikler (sayı, yüzde, ortalama, standart sapma) kullanılmıştır. Verilerin normal dağılıma uygunluğunu test etmek amacıyla Kolmogorov-Smirnov ve Shapiro-Wilk testleri uygulanmıştır. Normallik testleri sonucunda verilerin normal dağılım göstermediği belirlenmiş ve hakemlerin tanıtıcı özelliklerine göre karar verme stillerini incelemek amacı ile parametrik olmayan (Mann-Whitney $U$ ve Kruskal Wallis $H$ ) hipotez testleri uygulanmıştır. Çoklu gruplarda anlamlılığın hangi gruplardan kaynaklandığını belirlemek için Dunn-Bonferroni post-hoc testleri gerçekleştirilmiştir. İstatistiksel analizlerin değerlendirilmesinde p değeri .05 olarak kabul edilmiştir.

\section{Bulgular}

\section{Cinsiyet Değişkenine Göre Katılımcıların Karar Verme Puanları}

Çalışmaya katılım gösteren hakemlerin karar verme puanları cinsiyet değişkenine göre incelendiğinde tüm alt ölçeklerden (Dikkatli Karar Verme, Kaçıngan Karar Verme, Erteleyici Karar Verme, Panik Karar Verme) elde edilen puanların "cinsiyet” değişkenine göre istatistiksel olarak anlamlı bir farklılık göstermediği belirlenmiştir ( $p>.05)$ (Tablo.1).

Tablo 1. Mann Whitney - U Testi: Cinsiyet değişkenine göre karar verme puan dağılımı $(n=109)$.

\begin{tabular}{|c|c|c|c|c|c|c|}
\hline & Cinsiyet & $\mathrm{N}$ & Sıra Ort. & Sıra Top. & $\mathrm{U}$ & $p$ \\
\hline \multirow{2}{*}{ Öz saygı } & Kadın & 26 & 54,60 & 1419,50 & \multirow{2}{*}{1068,500} & \multirow{2}{*}{,936 } \\
\hline & Erkek & 83 & 55,13 & 4575,50 & & \\
\hline \multirow{2}{*}{ Dikkatli Karar Verme } & Kadın & 26 & 56,62 & 1472,00 & \multirow{2}{*}{1037,000} & \multirow{2}{*}{, 757} \\
\hline & Erkek & 83 & 54,49 & 4523,00 & & \\
\hline \multirow{2}{*}{ Kaçıngan Karar Verme } & Kadın & 26 & 52,62 & 1368,00 & \multirow{2}{*}{1017,000} & \multirow{2}{*}{, 654} \\
\hline & Erkek & 83 & 55,75 & 4627,00 & & \\
\hline \multirow{2}{*}{ Erteleyici Karar Verme } & Kadın & 26 & 63,60 & 1653,50 & \multirow{2}{*}{855,500} & \multirow{2}{*}{,100 } \\
\hline & Erkek & 83 & 52,31 & 4341,50 & & \\
\hline \multirow{2}{*}{ Panik Karar Verme } & Kadın & 26 & 61,92 & 1610,00 & \multirow{2}{*}{899,000} & \multirow{2}{*}{,180 } \\
\hline & Erkek & 83 & 52,83 & 4385,00 & & \\
\hline
\end{tabular}

\section{Medeni Durum Değişkenine Göre Katılımcıların Karar Verme Puanları}

Çalışmaya katılım gösteren hakemlerin karar verme puanları medeni durum değişkenine göre incelendiğinde tüm alt ölçeklerden (Dikkatli Karar Verme, Kaçıngan Karar Verme, Erteleyici Karar Verme, Panik Karar Verme) elde edilen puanların 
Öztürk Çelik, D. (2020). Farklı Spor Dallarında Görev Yapan Hakemlerin Karar Verme Stillerinin İncelenmesi. Gaziantep Üniversitesi Spor Bilimleri Dergisi, 5(4), 385-398

"medeni durum" değişkenine göre istatistiksel olarak anlamlı bir farklılık göstermediği belirlenmiştir ( $p>$.05) (Tablo.2)

Tablo 2. Mann Whitney - U Testi: Medeni durum değişkenine göre karar verme puan dağılımı

\begin{tabular}{lcccccc}
\hline & Medeni & $\mathrm{N}$ & Sıra Ort. & Sıra Top. & U & $\mathrm{p}$ \\
\hline \hline Ourum & Evli & 58 & 57,79 & 3352,00 & \multirow{2}{*}{1317,000} & \multirow{2}{*}{, 289} \\
& Bekar & 51 & 51,82 & 2643,00 & & \\
Dikkatli Karar Verme & Evli & 58 & 56,43 & 3273,00 & 1396,000 & \multirow{2}{*}{602} \\
Kaçıngan Karar & Bekar & 51 & 53,37 & 2722,00 & & \\
Verme & Evli & 58 & 54,45 & 3158,00 & 1447,000 & \multirow{2}{*}{, 844} \\
Erteleyici Karar Verme & Bekar & 51 & 55,63 & 2837,00 & & \\
\multirow{2}{*}{ Panik Karar Verme } & Evli & 58 & 54,74 & 3175,00 & \multirow{2}{*}{1464,000} & \multirow{2}{*}{925} \\
& Bekar & 51 & 55,29 & 2820,00 & & \multirow{2}{*}{, 162} \\
\hline
\end{tabular}

\section{Federasyon Değişkenine Göre Katılımcıların Karar Verme Puanları}

Çalışmaya katılım gösteren hakemlerin karar verme puanları hakemlerin bağlı olduğu federasyonu belirten federasyon değişkenine göre incelendiğinde, Melbourne karar verme ölçeğinin I. kısmını oluşturan "karar vermede öz saygı" puanlarının federasyon değişkenine göre anlamlı bir farklılık göstermediği belirlenmiştir ( $p>.05)$. Ayrıca hakemlerin, Melbourne karar verme ölçeğinin II. kısmı oluşturan ve karar vermenin alt boyutlarından olan "dikkatli karar verme", "erteleyici karar verme" ve "panik karar verme" puanları federasyon değişkenine göre incelendiğinde, dikkatli karar verme, erteleyici karar verme ve panik karar verme puanlarının üye olunan federasyona göre farklılık göstermediği belirlenmiştir ( $p>.05)$. Hakemlerin federasyon değişkenine göre kaçıngan karar verme puanları incelendiğinde federasyon değişkenine göre kaçıngan karar verme puanlarının anlamlı olarak farklılık gösterdiği $(\mathrm{KW}=9,754, \mathrm{p}<.05)$ belirlenmiştir. Gerçekleştirilen Dunn-Bonferroni post-hoc testi sonucunda federasyon değişkenine göre kaçıngan karar verme puanları arasındaki farkın Voleybol-Basketbol, Futbol-Basketbol gruplarından kaynaklandığı tespit edilmiştir (Tablo. 3). 
Tablo 3. Kruskal-Wallis H Testi: Federasyon değişkenine göre karar verme puan dağılımı

\begin{tabular}{|c|c|c|c|c|c|c|c|}
\hline & Federasyon & $\mathrm{N}$ & Sira Ort. & $\mathrm{KW}$ & $\mathrm{df}$ & $\mathrm{p}$ & Post-hoc \\
\hline \multirow{3}{*}{ Öz saygı } & Voleybol & 29 & 52,40 & \multirow{3}{*}{2,163} & \multirow{3}{*}{2} & \multirow{3}{*}{,339 } & \\
\hline & Futbol & 54 & 59,04 & & & & \\
\hline & Basketbol & 26 & 49,52 & & & & \\
\hline \multirow{3}{*}{ Dikkatli Karar Verme } & Voleybol & 29 & 60,22 & \multirow{3}{*}{4,145} & \multirow{3}{*}{2} & \multirow{3}{*}{,126 } & \\
\hline & Futbol & 54 & 49,01 & & & & \\
\hline & Basketbol & 26 & 61,62 & & & & \\
\hline \multirow{3}{*}{$\begin{array}{l}\text { Kaçıngan Karar } \\
\text { Verme }\end{array}$} & Voleybol & 29 & 47,34 & \multirow{3}{*}{9,754} & \multirow{3}{*}{2} & \multirow{3}{*}{, $008^{*}$} & \\
\hline & Futbol & 54 & 51,22 & & & & $\begin{array}{l}-B \\
F-B\end{array}$ \\
\hline & Basketbol & 26 & 71,38 & & & & \\
\hline \multirow{3}{*}{ Erteleyici Karar Verme } & Voleybol & 29 & 60,10 & \multirow{3}{*}{2,089} & \multirow{3}{*}{2} & \multirow{3}{*}{,352 } & \\
\hline & Futbol & 54 & 50,80 & & & & \\
\hline & Basketbol & 26 & 58,04 & & & & \\
\hline \multirow{3}{*}{ Panik Karar Verme } & Voleybol & 29 & 52,31 & \multirow{3}{*}{,400 } & \multirow{3}{*}{2} & \multirow{3}{*}{,819 } & \\
\hline & Futbol & 54 & 55,29 & & & & \\
\hline & Basketbol & 26 & 57,40 & & & & \\
\hline
\end{tabular}

${ }^{*} \mathrm{p}<.05$ F: Futbol, V: Voleybol, B: Basketbol

\section{Hakemlik Yılına Göre Katılımcıların Karar Verme Puanları}

Çalışmaya katılım gösteren hakemlerin karar verme puanları hakemlik yılı değişkenine göre incelendiğinde, karar vermede öz saygı puanlarının hakemlik yılı değişkenine göre anlamlı olarak farklılık gösterdiği $(\mathrm{KW}=12,066, p<.05)$ belirlenmiştir. Dunn-Bonferroni post-hoc testi sonucunda hakem yılı değişkenine göre öz saygı puanları arasındaki farkın 1-5, 11-15 hakemlik yılına ait gruplardan kaynaklandığı tespit edilmiştir. Hakemlerin dikkatli karar verme ve erteleyici karar verme puanları hakemlik yılı değişkenine göre incelendiğinde, dikkatli karar verme ve erteleyici karar verme puanlarının hakemlik yılı değişkenine göre anlamlı farklılık göstermediği belirlenmiştir ( $\mathrm{KW}_{\text {Dikkatli Karar Verme }}=1,618, \mathrm{KW}_{\text {Erteleyici Karar Verme }}=7,410$, p>.05). Hakemlerin kaçıngan karar verme puanları hakemlik yılı değişkenine göre incelendiğinde, kaçıngan karar verme puanlarının hakemlik yılı değişkenine göre anlamlı olarak farklılık gösterdiği belirlenmiştir (KW=10,459, p<.05). Gerçekleştirilen Dunn-Bonferroni post-hoc testi sonucunda hakemlik yılı değişkenine göre kaçıngan karar verme puanları arasındaki farkın 11-15, 6-10 hakemlik yılına ait gruplardan kaynaklandığı belirlenmiştir. Hakemlerin panik karar verme puanları hakemlik yılı değişkenine göre incelendiğinde, panik karar verme puanlarının hakemlik yılı 
değişkenine göre anlamlı olarak farklılık gösterdiği (KW $=10,290, \quad p<.05)$ belirlenmiştir. Gerçekleştirilen Dunn-Bonferroni post-hoc testi sonucunda hakemlik yılı değişkenine göre panik karar verme puanları arasındaki farkın 6-10, 1-5 hakemlik yılına ait gruptan kaynaklandığı tespit edilmiştir (Tablo.4).

Tablo 4. Kruskal-Wallis H Testi: Hakemlik yılı değişkenine göre karar verme puan dağılımı

\begin{tabular}{|c|c|c|c|c|c|c|c|}
\hline & $\begin{array}{c}\text { Hakemlik } \\
\text { Yılı } \\
\end{array}$ & $\mathrm{N}$ & Sıra Ort. & KW & $\mathrm{df}$ & $\mathrm{p}$ & Post-Hoc \\
\hline \multirow{4}{*}{ Öz saygı } & $1-5$ & 53 & 46,18 & \multirow{4}{*}{12,066} & \multirow{4}{*}{3} & \multirow{4}{*}{,007* } & \multirow{4}{*}{$(1-5)-(11-15)$} \\
\hline & $6-10$ & 20 & 61,38 & & & & \\
\hline & $11-15$ & 21 & 71,07 & & & & \\
\hline & 16 ve üzeri & 15 & 55,17 & & & & \\
\hline \multirow{4}{*}{ Dikkatli Karar Verme } & $1-5$ & 53 & 51,93 & \multirow{4}{*}{1,618} & \multirow{4}{*}{3} & \multirow{4}{*}{,655 } & \\
\hline & $6-10$ & 20 & 55,33 & & & & \\
\hline & $11-15$ & 21 & 61,90 & & & & \\
\hline & 16 ve üzeri & 15 & 55,73 & & & & \\
\hline \multirow{4}{*}{$\begin{array}{l}\text { Kaçıngan Karar } \\
\text { Verme }\end{array}$} & $1-5$ & 53 & 56,21 & \multirow{4}{*}{10,459} & \multirow{4}{*}{3} & \multirow{4}{*}{, $015^{*}$} & \multirow{4}{*}{$(11-15)-(6-10)$} \\
\hline & $6-10$ & 20 & 67,25 & & & & \\
\hline & $11-15$ & 21 & 37,07 & & & & \\
\hline & 16 ve üzeri & 15 & 59,50 & & & & \\
\hline \multirow{4}{*}{ Erteleyici Karar Verme } & $1-5$ & 53 & 60,48 & \multirow{4}{*}{7,410} & \multirow{4}{*}{3} & \multirow{4}{*}{,060 } & \\
\hline & $6-10$ & 20 & 52,70 & & & & \\
\hline & $11-15$ & 21 & 39,81 & & & & \\
\hline & 16 ve üzeri & 15 & 59,97 & & & & \\
\hline \multirow{4}{*}{ Panik Karar Verme } & $1-5$ & 53 & 63,92 & \multirow{4}{*}{10,290} & \multirow{4}{*}{3} & \multirow{4}{*}{,016* } & \multirow{4}{*}{$(6-10)-(1-5)$} \\
\hline & $6-10$ & 20 & 41,50 & & & & \\
\hline & $11-15$ & 21 & 46,62 & & & & \\
\hline & 16 ve üzeri & 15 & 53,23 & & & & \\
\hline
\end{tabular}

${ }^{*} \mathrm{p}<.05$

\section{Hakemlik Yapılan Spor Dalına Ait Federasyonda Antrenörlük Yapma Durumuna Göre Karar Verme Puanları}

Çalışmaya katııım gösteren hakemlerin karar verme puanları "hakemlik yapılan spor dalına ait federasyonda antrenörlük yapma" durumuna göre incelendiğinde, karar vermede öz saygı, dikkatli karar verme, kaçıngan karar verme, panik karar verme puanlarının "hakemlik yapılan spor dalına ait federasyonda antrenörlük yapma" değişkenine göre anlamlı farklılık göstermediği belirlenmiştir ( $p>$.05). Erteleyici karar verme puanlarının ise "hakemlik yapılan spor dalına ait federasyonda 
Öztürk Çelik, D. (2020). Farklı Spor Dallarında Görev Yapan Hakemlerin Karar Verme Stillerinin İncelenmesi. Gaziantep Üniversitesi Spor Bilimleri Dergisi, 5(4), 385-398

antrenörlük yapma” değişkenine göre anlamlı bir farklılık gösterdiği tespit edilmiştir $(p<.05)$ (Tablo.5).

Tablo 5. Mann Whitney - U Testi: Aynı federasyonda antrenörlük yapma durumuna göre karar verme puan dağılımı $(n=109)$.

\begin{tabular}{lcccccc}
\hline & $\begin{array}{c}\text { Antrenörlük } \\
\text { Durumu }\end{array}$ & N & Sıra Ort. & Sıra Top. & U & p \\
\hline \hline \multirow{2}{*}{ Öz saygı } & Evet & 21 & 55,12 & 1157,50 & 921,500 &, 983 \\
& Hayır & 88 & 54,97 & 4837,50 & & \\
Dikkatli Karar Verme & Evet & 21 & 57,88 & 1215,50 & 863,500 &, 631 \\
& Hayır & 88 & 54,31 & 4779,50 & & \\
Kaçıngan Karar Verme & Evet & 21 & 64,14 & 1347,00 & 732,000 &, 134 \\
& Hayır & 88 & 52,82 & 4648,00 & & \\
Erteleyici Karar Verme & Evet & 21 & 68,62 & 1441,00 & 638,000 &, 023 \\
& Hayır & 88 & 51,75 & 4554,00 & & \\
Panik Karar Verme & Evet & 21 & 54,17 & 1137,50 & & \\
\hline *p<.05 & Hayır & 88 & 55,20 & 4857,50 & 906,500 & \\
\hline
\end{tabular}

\section{Eğitim Durumuna Göre Katılımcıların Karar Verme Puanları}

Çalışmaya katılım gösteren hakemlerin karar verme puanları eğitim değişkenine göre incelendiğinde karar verme puanlarının tüm alt boyutlarının eğitim değişkenine göre istatistiksel olarak anlamlı fark göstermediği belirlenmiştir ( $p>.05)$ (Tablo.6).

Tablo 6. Kruskal-Wallis H Testi: Eğitim durumuna göre karar verme puan dağılımı (

\begin{tabular}{|c|c|c|c|c|c|c|}
\hline & Eğitim Durumu & $\mathrm{N}$ & Sira Ort. & KW & $\mathrm{df}$ & $\mathrm{p}$ \\
\hline \multirow{3}{*}{ Öz saygı } & Lise & 26 & 46,29 & & & \\
\hline & Ön lisans- Üniversite & 71 & 59,49 & 4,797 & 2 & ,091 \\
\hline & Lisansüstü & 12 & 47,29 & & & \\
\hline \multirow{3}{*}{ Dikkatli Karar Verme } & Lise & 26 & 59,75 & & & \\
\hline & Ön lisans- Üniversite & 71 & 52,79 & 1,101 & 2 & 577 \\
\hline & Lisansüstü & 12 & 57,79 & & & \\
\hline \multirow{3}{*}{ Kaçıngan Karar Verme } & Lise & 26 & 61,33 & & & \\
\hline & Ön lisans- Üniversite & 71 & 53,55 & 1,554 & 2 & ,460 \\
\hline & Lisansüstü & 12 & 49,88 & & & \\
\hline \multirow{3}{*}{ Erteleyici Karar Verme } & Lise & 26 & 59,25 & & & \\
\hline & Ön lisans- Üniversite & 71 & 53,04 & 868 & 2 & 648 \\
\hline & Lisansüstü & 12 & 57,38 & & & \\
\hline \multirow{3}{*}{ Panik Karar Verme } & Lise & 26 & 65,90 & & & \\
\hline & Ön lisans- Üniversite & 71 & 50,44 & ,868 & 2 & ,076 \\
\hline & Lisansüstü & 12 & 58,38 & & & \\
\hline
\end{tabular}




\section{Tartışma ve Sonuç}

Spor müsabakaları yöneten hakemlerin karar verme stillerinin incelendiği bu çalışmada futbol federasyonu, voleybol federasyonu, basketbol federasyonu bünyesinde yer alan hakemlerden oluşan örneklem grubuna Melbourne karar verme ölçeğinin I. kısımda karar vermede öz saygı, II. kısımda dikkatli karar verme, kaçıngan karar verme, erteleyici karar verme, panik karar verme alt boyutları uygulanmış ve yorumlanmıştır.

Spor müsabakalarında görev alan hakemlerin cinsiyet değişkeni puanlarına göre karar vermede öz saygı ve karar verme alt boyutlarında istatistiksel olarak anlamlı bir farklıığa rastlanmamıştır. Çalışmanın sonuçlarını destekler nitelikte geçmişte araştırmacılar tarafından farklı gruplar ile (öğrenci, öğretmen, sporcu vb.) gerçekleştirilen çalışmalarda karar verme puanlarının cinsiyet değişkenine göre istatistiksel olarak anlamlı bir farklılık göstermediği belirlenmiştir (Avşaroğlu ve Ömer, 2007; Balcanlı ve Sürücü, 2006; Çetin, 2009; Dilmaç ve Bozgeyikli, 2009; Kelecek ve ark., 2013; Kurt, 2016; Salo ve Allwood, 2011; Tekin ve ark., 2009; Temur, 2012).

Çalışmada hakemlerin karar vermede öz saygı ve karar verme puanlarının "medeni durum" değişkenine göre istatistiksel olarak anlamlı bir farklılık göstermediği belirlenmiştir. (Atakan ve Arslan, 2020) çalışmalarında hakemlerin medeni durumlarının karar vermede öz saygı puanlarını istatistiksel olarak anlamlı bir farklılık olmadığını tespit etmişlerdir.

Çalışmada hakemlerin görev aldıkları federasyon değişkenine göre karar verme alt boyutlarından "kaçıngan karar verme" puanları arasında istatistiksel olarak anlamlı bir farklılık olduğu belirlenmiş farkın futbol-basketbol, voleybol-basketbol hakemlerinden kaynaklandığı tespit edilmiştir. (Kırtepe ve Çetinkaya, 2018) çalışmalarında federasyon değişkenine göre istatistiksel olarak anlamlı farklılık olmadığını tespit etmişlerdir.

Yapılan çalışmada hakemlik yılı değişkenine göre "Toplam öz saygı" puanları arasındaki farkın 1-5, 11-15 hakemlik yıllarına ait gruplardan kaynaklandığı belirlenmiştir. Hakemlik yılı değişkenine göre "kaçıngan karar verme" puanları arasındaki farkın 11-15, 6-10 hakemlik yılına ait gruplardan kaynaklandığı, "Panik karar verme" puanları arasındaki farkın 6-10, 1-5 hakemlik yılına ait gruptan kaynaklandığı tespit edilmiştir. Literatürde çalışma sonuçlarımızı destekleyen geçmiş çalışmalar bulunmaktadır. Atılgan ve Tükel, (2019) çalışmalarında hakemlerin kıdem yılı değişkenine göre kaçıngan karar verme puanlarında istatistiksel olarak anlamlı bir 
farklılık olduğunu belirlemişlerdir. Sarıdede, (2018) çalışmasında hakemlik yılının kaçıngan karar verme ve panik karar verme puanlarında istatistiksel olarak anlamlı farklılık olduğunu tespit etmiştir.

Çalışamaya katılım gösteren hakemlerin aynı federasyonda antrenörlük yapma durumuna göre hakemlerin karar verme puanları incelendiğinde "Erteleyici karar verme" puanları arasında istatistiksel olarak anlamı bir farklılık tespit edilmiştir. Bu sonuçtan antrenör hakemlerin karar verirken hatalı davranış ve kuralları anında karar vermeyerek erteleyici karar vermeyi seçtikleri düşünülebilir.

Çalışmaya katılım gösteren hakemlerin karar verme puanları eğitim değişkenine göre incelendiğinde anlamlı bir farklılık göstermediği belirlenmiştir. Çalışmanın sonuçlarını destekler nitelikte geçmişte araştırmacılar tarafından (üye, yönetici, sporcu vb.) gerçekleştirilen çalışmalarda karar verme puanlarının eğitim değişkenine göre istatistiksel olarak anlamlı bir farklılık göstermediği belirlenmiştir (Pulur ve Akcan, 2017; Utku ve Cengiz, 2018; Vural, 2013).

Sonuç olarak, farklı spor dallarında görev yapan hakemlerin karar verme sitillerinin hakemlik yaptığı federasyon, hakemlik yılı, hakemlik yapılan spor dalına ait federasyonda antrenörlük yapma durumu değişkenlerinin istatistiksel olarak anlamlı farklılık gösterdiği belirlenirken, eğitim, cinsiyet, medeni durum değişkenlerinin istatiksel olarak farklılık göstermediği belirlenmiştir.

Hakemler, önceden belirlenmiş kurallar çerçevesinde spor müsabakalarını yöneten, müsabakalarda alınan puanları ve cezaları belirleyen kişilerdir (Demirel, M. 2007). Spor müsabakalarında, hakem kararlarının doğru ve uygun sürede verilmiş olması önem arz etmektedir. Bu nedenle hakemlerin karar verme sürecinde yararlandıkları karar verme stratejileri ve karar verme stillerinin incelenmesi doğru karar verme süreci bakımından önemlidir. Bu çalışmada basketbol, voleybol ve futbol spor dallarında görev yapan hakemlerin karar verme stilleri farklı demografik değişkenler açısından incelenmiştir. Çalışmanın bulgularının, incelenmiş olan spor dallarındaki hakemlerin karar verme stratejilerinin analizi, geliştirilmesi ve hatalı kararların en aza indirgenmesine yönelik çalışmaların yapılabilmesi adına ilgili spor federasyon yöneticilerine önemli bilgiler sağlayacağı düşünülmektedir. 


\section{Kaynaklar}

Atakan, A., \& Arslan, C. (2020). Farklı Klasmandaki Futbol Hakemlerinin Karar Verme Stillerinin İncelenmesi. Spor Eğitim Dergisi, 4(1), 56-70.

Atılgan, D., \& Tükel, Y. (2019). Hakemlerin Karar Verme Stillerinin İncelenmesi. Sport Sciences, 14(2), 22-32.

Avşaroğlu, S., \& Ömer, Ü. (2007). Üniversite Öğrencilerinin Karar Vermede Özsaygi, Karar Verme Ve Stresle Başaçikma Stillerinin Benlik Saygisi Ve Bazi Değişkenler Açisindan İncelenmesi. Selçuk Üniversitesi Sosyal Bilimler Enstitüsü Dergisi(18), 85-100.

Balcanlı, F., \& Sürücü, M. (2006). ilköğretim 8. sınıf öğrencilerinin sınav kaygıları ve karar verme stilleri arasındaki ilişkilerin incelenmesi. Kuram ve Uygulamada Eğitim Yönetimi, 45(45), 7-35.

Büyüköztürk Ş, Kılıç Çakmak E, Akgün ÖE, Karadeniz Ş, Demirel F (2017): Bilimsel araştırma yöntemleri, 23. baskı, Ankara: Pegem Akademi.

Cengiz, R., \& Pulur, A. (2004). Hakemlerin Fair Play Olaylarına Bakış Açıları. Celal Bayar Üniversitesi Spor Felsefesi ve Sosyal Bilimleri Sempozyumu, 17-20.

Çetin, M. Ç. (2009). Beden eğitimi ve spor yüksekokulu öğrencilerinin karar verme stilleri, sosyal beceri düzeyleri ve stresle başa çıkma biçimlerinin bazı değişkenler açısından karşılaştırmalı olarak incelenmesi. Doktora Tezi, Gazi Üniversitesi, Ankara, Türkiye.

Çolakkadıoğlu, O. (2010). Çatışma kuramına dayalı olarak geliştirilen karar verme beceri eğitimi grup uygulamalarının ergenlerin karar verme stillerine etkisi. Unpublished doctoral thesis. Çukurova University, Adana, Turkey. ,

Demirel, M., Atalay, K., Şentürk, A., Demirel, D. H., \& Serdar, E. Investigation of Muay Thai Referees' Decision-making Strategies According to Different Variables. Research in Sports Science, 9(1), 5-10.

Deniz, M. E. (2011). Karar verme stilleri ve beş faktör kişilik özelliklerinin bağlanma stilleri açısından incelenmesi. Kuram ve Uygulamada Eğitim Bilimleri, 11(1), 97-113.

Dilmaç, B., \& Bozgeyikli, H. (2009). Öğretmen Adaylarinin Öznel İyi Olma ve Karar Verme Stillerinin İncelenmesi. Erzincan Üniversitesi Eğitim Fakültesi Dergisi, 11(1).

Durna, E. (1997). Türkiye'de Futbol ve Hakem. Yıldızlar Matbaacılık. İstanbul. 
Eskicioğlu, Y., Doğu, G., \& Özsoy, S. (2012). Antrenör ve sporcu gözüyle spor yöneticilerinin kararlarında etik ilkelere bağlılıklarının incelenmesi (Beko Basketbol Ligi örneği). İstanbul Üniversitesi Spor Bilimleri Dergisi, 4(1-2), 1322.

Güçray, S. S. (2001). Ergenlerde karar verme davranışlarının öz saygı ve problem çözme becerileri algısı ile ilişkisi. Çukurova Üniversitesi Sosyal Bilimler Enstitüsü Dergisi, 8(8).

Kelecek, S., Altındaş, A., \& Aşçı, F. H. (2013). Sporcuların karar verme stillerinin belirlenmesi. CBÜ Beden Eğitimi ve Spor Bilimleri Dergisi, 8(1), 21-27.

Kırtepe, A., \& Çetinkaya, T. (2018). Farkli Branştaki Hakemlerin Karar Verme Stillerinin Bazi Değişkenler Açisindan İncelenmesi. Electronic Turkish Studies, 13(10).

Kurt, E. (2016). Orta Öğretim Öğrencilerinin Karar Verme Stratejilerinin Bazı Değişkenler Açısından İncelenmesi. Yüksek Lisans Tezi, Karadeniz Teknik Üniversitesi Eğitim Bilimleri Enstitüsü ....

Pekdoğan, S. (2015). Karar verme stilleri araştırmaları: 2009-2013 yılları arasındaki yüksek lisans tezlerinin incelenmesi. International Journal of Social Science, 34, 321-331.

Pulur, A., \& Akcan, İ. O. (2017). Elit Oryantiring Sporcularının Görsel Reaksiyon Süreleri ile Karar Verme Stilleri Arasındaki İlişki. Gaziantep Üniversitesi Spor Bilimleri Dergisi, 2(1), 53-61.

Salo, I., \& Allwood, C. M. (2011). Decision-making styles, stress and gender among investigators. Policing: An International Journal of Police Strategies \& Management.

Sarıdede, Ç. (2018). Voleybol hakemlerinin öz yeterlik düzeyleri ve karar verme becerilerinin incelenmesi. İstanbul Gelişim Üniversitesi Sağlık Bilimleri Enstitüsü.

TDK. (2020). http://www.tdk.gov.tr. Erişim Tarihi: 12.07.2020, Adres: www.tdk.gov.tr

Tekin, M., Özmutlu, İ., \& Erhan, S. E. (2009). Özel Yetenek Sinavlarina Katilan Öğrencilerin Karar Verme ve Düşünme Stillerinin İncelenmesi. Journal of Physical Education and Sport Sciences, 11(3).

Temur, Ö. F. (2012). Öğretmen algılarına göre yöneticilerin karar verme stillerinin öğretmenlerin örgütsel bağlılığına etkisi: Rize ili örneği. Recep Tayyip Erdoğan Üniversitesi/Sosyal Bilimler Enstitüsü/Illköğretim. 
Tosun, K. (1992). İşletme Yönetimi Genel Esaslar (Altıncı Baskı). Ankara: Savaş Kitap ve Yayınevi.

Utku, I., \& Cengiz, R. (2018). Doğa kulüplerine üye bireylerin zaman yönetimi ve karar verme stillerinin incelenmesi. SPORMETRE Beden Eğitimi ve Spor Bilimleri Dergisi, 16(2), 25-35.

Üngüren, E. (2011). Psikobiyolojik kişilik kuramı ekseninde yöneticilerin kişilik özellikleri, karar verme stilleri ve örgütsel sonuçlara yansımaları. Akdeniz Üniversitesi Sosyal Bilimler Enstitüsü, Antalya.

Vural, M. (2013). Spor genel müdürlüğü merkez ve taşra teşkilatında görev yapan spor yöneticilerinin düşünme ve karar verme stillerinin incelenmesi. Selçuk Üniversitesi Sağlık Bilimleri Enstitüsü. 